\title{
How important are scale effects for growth when knowledge is a public good?*
}

\author{
Fernando Sánchez-Losada ${ }^{\dagger}$ \\ Departament d'Economia, CREB and BEAT \\ Universitat de Barcelona
}

\begin{abstract}
This paper seeks to reconcile the following three facts: the positive relationship between the fraction of income allocated to R\&D expenditure and growth, the positive relationship between the number of firms and total factor productivity growth, and knowledge as a nonrival and nonexcludable good, by proposing a particular R\&D accumulation law in an economy with an expanding number of firms. Thus, and in contrast with previous R\&D-variety growth models, we have scale effects because of the public nature of knowledge, but the economy also grows in the absence of population growth. The contribution of population growth to economic growth is calculated and, hence, the contribution to growth of the public good nature of knowledge is shown. We find that population growth explains one fifth of market income growth but only one sixteenth of efficient income growth. This means that population is not as important for growth when inefficiencies are removed.
\end{abstract}

Keywords: knowledge, public good, growth

J.E.L. Classification Code: O30, O40, O41

\footnotetext{
${ }^{*}$ I acknowledge useful comments received from one anonymous referee, the participants at the UB Macro Internal Seminar, Daniel Cardona, David Cuberes, Patricio García-Mínguez, Vahagn Jerbashian, Charles I. Jones, Xavier Raurich, Ausias Ribó and would especially like to thank Edgar Cruz for his time. I am grateful for financial support from the Ministerio de Economía y Competitividad and Fondo Europeo de Desarrollo Regional through grant ECO2015-66701-R (MINECO/FEDER, UE) and from the Government of Catalonia through grant 2014SGR 493 .

†fernando.sanchezlosada@ub.edu
} 


\section{R\&D-variety growth models and scale effects}

In recent years there has been some discussion as to which of the following growth models provides a better explanation of technological progress: R\&Dvariety growth models or Schumpeterian models. In R\&D-based models of growth (see Jones, 1995), a positive increase in R\&D resources is required to maintain sustained growth given the assumption of diminishing returns to knowledge. Hence, a rising supply of researchers is needed. This implies that growth is explained exclusively by scale effects and, therefore, an economy with zero population growth experiences zero income growth. In contrast, in Schumpeterian models (see Dinopoulos and Thompson, 1998), there is a positive relation between the fraction of income allocated to R\&D expenditure and economic growth. This implies growth without scale effects.

In principle, the empirical evidence supports Schumpeterian models - see Zachariadis (2003) and Madsen (2008). But at the same time, these papers suggest that this conclusion could also be reached by the diminishing returns to knowledge assumed in the R\&D-variety growth models and, as such, they support the findings of Madsen (2007) and Venturini (2012). While the former concludes that R\&D might be characterized by constant returns to scale, the latter reports that knowledge production functions based on the expansion of variety overlook some relevant institutional and policy factors. Indeed, developed countries during the 20th century were characterized by a negative relationship between population growth and economic growth (see Galor and Weil, 2000). In order to reconcile the R\&D-variety growth model and this circumstance, Strulik et al. (2013) introduce the Beckerian child quantity-quality trade-off. ${ }^{1}$

However, the importance for growth of scale effects in their own right as well as via agglomeration economies has been broadly documented. For example, Nickell (1996) shows that an increase in the number of firms is associated with a higher rate of total factor productivity (TFP) growth. Álvarez-Peláez and Groth (2005), likewise, highlight the importance of the returns to specialization for growth. Ciccone and Hall (1996) find that doubling employment density increases average labor productivity by 6 percent, whereas Davis et al. (2014) estimate that the impact of local agglomeration on the growth rate is about 10 percent. Therefore, since competition increases as the number of firms grows, competition drives growth, as Nickell (1996) has shown empirically. In other words, an increased number of competitors in the same industry is positively correlated with TFP growth. Thus, an R\&D-variety growth model should at least explain a significant part of this growth.

At the same time, it seems clear that since knowledge is nonrival and nonexcludable, population matters in the determination of growth. The rationale is that an increase in population makes an increase in knowledge more likely, which at the same time is to the benefit of the population. From an economic point of view, it is therefore clear that as knowledge is a public good, endogenous growth

\footnotetext{
${ }^{1}$ The connection between growth, human capital and the child quantity-quality trade-off had been previously shown by Zhang (1995) and Zhang and Zhang (2003) among many others.
} 
exhibits some kind of scale effects. ${ }^{2}$ This positive correlation between growth and technological advancement or knowledge, and population growth, has been empirically shown in Kremer (1993) for the very long run.

This paper seeks to reconcile these three facts - the positive relationship between the fraction of income allocated to $R \& D$ expenditure and growth; the positive relationship between the number of firms and TFP growth; and, knowledge as a nonrival and nonexcludable good - by proposing a particular R\&D accumulation law in an economy with an expanding number of firms. Thus, and in contrast with previous R\&D-variety growth models, scale effects are recognized because of the public nature of knowledge, but the economy also grows in the absence of population growth. In other words, scale effects are not necessary to obtain growth; population growth only spurs economic growth. The contribution of population growth to economic growth is calculated and, hence, the contribution to growth of the public good nature of knowledge is shown. The paper finds that population growth accounts for one fifth of market income growth but only one sixteenth of efficient income growth. This means that population is not as important for growth when inefficiencies are removed.

Schumpeterian growth models, such as those proposed by Segerstrom (1998) and Young (1998), eliminate scale effects at the same time as they predict that product quality improvements are crucial in explaining growth. Thus, the economy grows in the absence of population growth. But as Schumpeterian growth models are based on the existence of monopolies, they cannot explain Nickell's (1996) evidence indicating that competition drives growth. Moreover, this positive correlation between competition and productivity growth has been shown empirically by Geroski (1995), Blundell et al. (1999), and Aghion et al. (2004), who report a positive relation between competition and innovative activity. In this paper, an increase in the number of firms raises productivity. Given that in our economy the emergence of a new firm means a new product or variety, and given also that Bernard et al. (2010) show that product creation (in new and existing firms) accounts for almost 50 percent of output each five-year interval and Bils and Klenow (2001) report a variety growth of about 1 percent per year between 1959 and 1999, accelerating by about 1 percent between the first and second halves of the sample (i.e. 1979 to 1999 relative to 1959 to 1979), new firms and competition could be crucial in explaining growth.

Subsequent variants of Schumpeterian growth models, such as those developed by Peretto (1998) and Laincz and Peretto (2006), assume a combination of private and public knowledge. Firms undertake $R \& D$ in order to accumulate proprietary knowledge that will be converted into public knowledge, where the latter is the weighted average of the knowledge of all firms, with the weights being determined by the firms' market shares. Thus, the size of the firm determines the weight of the new invention in new knowledge, assuming implicitly that the importance of new knowledge does not depend on itself. The problem with this approach to the modelling of private knowledge is two-fold. First, it does not deal exactly with proprietary or private knowledge, but rather with

\footnotetext{
${ }^{2}$ See Jones (1999) for an exhaustive review of this literature.
} 
knowledge that can be privately exploited for just one period. In other words, a firm's present-day $R \& D$ does not depend on its own past $R \& D$, but rather on past aggregate R\&D. Moreover, proprietary knowledge should have a market price by means of some type of knowledge licensing, as in Jerbashian (2016). Second, the question arises as to why public knowledge is not the sum of all the firms' knowledge rather than a weighted sum of all the firms' knowledge. This would appear to be merely a mathematical solution to the scale effects problem, but one without any economic foundation. ${ }^{3}$ It seems that the problem is more one of diffusion: new knowledge diffuses more slowly if the firm is small, but in the long run this knowledge does become part of aggregate knowledge. But, at the same time, it might also be due to the fact that knowledge may be more industry oriented (although it can be used in other sectors). Thus, the profitability of one firm's R\&D for all other firms would depend on the sector in which the other firms operate (as in Raurich et al., 2015).

The paper is organized as follows. In the next section, we study the relationship between the public good nature of knowledge and scale effects, and propose a knowledge production function that generates growth even in the absence of population growth. As in Segerstrom (1998) and Young (1998), we first analyze the market economy and then the socially optimal growth rate. Thus, in section 3 we present the market economy while in section 4 we compute the contribution of population growth to income growth through a calibration of the economy. In section 5, we compare our previous results when inefficiencies are removed. This allows us to show the importance of the public good nature of knowledge for the economy. Finally, section 6 concludes.

\section{Knowledge as a public good and scale effects}

Consider an economy with two technologies: one for final goods $Y$ and one for knowledge $A$. Final goods are private goods while knowledge is a public good. This has one very important implication: final goods can be written in per capita terms, but knowledge cannot, since all of us benefit from it in the same way. This could give rise to some kind of scale effects: the size of population matters in the determination of knowledge and, in turn, in the determination of per capita income.

First, let us consider the final goods sector. Total population $L$ works either producing goods $L_{Y}$ or producing knowledge $L_{A}$. Since both labor inputs are a proportion of total labor, define $L_{A}=s L$ and $L_{Y}=(1-s) L$, where $s$ is the proportion of labor employed in the knowledge sector. The technology of a final goods firm that chooses the amount of capital $K$ and labor $L_{Y}$ can be summarized as

$$
Y=\left(A L_{Y}\right)^{\alpha} K^{1-\alpha},
$$

where $\alpha \in(0,1)$. By defining the variables per efficiency units of labor, $\widetilde{y}=$

\footnotetext{
${ }^{3}$ According to this approach, Microsoft added almost nothing to aggregate knowledge, since at the outset it was very small (compared to IBM, for example).
} 
$Y / A L$ and $\widetilde{k}=K / A L$, this technology can be rewritten as

$$
\widetilde{y}=(1-s)^{\alpha} \widetilde{k}^{1-\alpha} .
$$

Hence, a balanced growth path (BGP) exists if $\widetilde{k}$ is constant, that is, if $K$ grows at the same rate as $A L$, i.e. $\dot{K} / K=\dot{A} / A+\dot{L} / L$. This means that per capita income grows at the same rate as knowledge.

Let us now consider the knowledge sector. Since knowledge is a public good, endogenous growth exhibits some kind of scale effects. Since Jones (1995), dozens of R\&D-variety growth models have been proposed in which growth is exclusively explained by scale effects. That is, without scale effects an economy cannot experience growth. This means that an economy with zero population growth experiences zero income growth. Next, we argue that this implication is exclusively the result of the technologies chosen for the production of knowledge. In particular, we propose an $R \& D$ production function that allows the economy to experience positive income growth even in the absence of population growth, although we still have scale effects given the public good nature of knowledge. That is, population growth spurs economic growth, but it is not necessary for economic growth to occur.

The increase in knowledge $\dot{A}$ arises from the production of new designs in the R\&D sector, since although the firm that discovers a new design is the only firm that can produce it, the new design is publicly available. In Romer (1990), the technology of an R\&D firm that produces $\dot{A}$ and chooses the amount of labor $L_{A}$ is

$$
\dot{A}=\delta L_{A} A,
$$

where $\delta$ is the probability of success that any researcher has of inventing a new design in any period. Note that the new knowledge $\dot{A}$ discovered by one particular firm constitutes common knowledge for the rest of the firms. Rewriting this equation, yields

$$
\frac{\dot{A}}{A}=\delta s L,
$$

so that constant population is needed for a BGP to exist. Note that the higher the number of researchers, the higher the growth rate. Moreover, for the same proportion of labor employed in the R\&D sector, the economy with a higher population experiences higher income growth. Thus, the economy exhibits scale effects.

In Jones (1995), the technology of an R\&D firm is

$$
\dot{A}=\delta L_{A} A^{\phi} l_{A}^{\lambda-1},
$$

where $\phi$ represents external returns and it can take any sign, $l_{A}$ represents an externality due to duplication in R\&D such that in equilibrium $l_{A}=L_{A}$, and $0<\lambda \leq 1$. Rewriting this equation, in equilibrium we have

$$
\frac{\dot{A}}{A}=\frac{\delta s^{\lambda} L^{\lambda}}{A^{1-\phi}},
$$


so that $L^{\lambda} A^{\phi-1}$ has to be constant for a BGP to exist. If population grows at rate $n$, this is true whenever

$$
\frac{\dot{A}}{A}=\frac{\lambda n}{1-\phi},
$$

so that when the population is constant we (asymptotically) have no growth at all. Further, growth is independent of both the probability of R\&D success and the proportion of labor employed in the knowledge sector. Moreover, the economy with higher population growth experiences higher income growth. Thus, the economy also exhibits scale effects. Therefore, we can say that Romer's economy has absolute scale effects whereas Jones' economy has relative scale effects.

The two previous R\&D technologies were able to explain R\&D over many centuries. But from at least the 17th century (see Mokyr, 2013, for past and present examples), almost all R\&D has not only been conducted with researchers, but also with physical capital, including laboratories and microscopes. Following Rivera-Batiz and Romer (1991), consider now the following technology of an R\&D firm that chooses the amount of labor $L_{A}$ and capital $K_{A}$ :

$$
\dot{A}=\delta\left(A L_{A}\right)^{\gamma} K_{A}^{1-\gamma},
$$

where $\gamma \in(0,1)$. Redefining the capital used in the final goods production by $K_{Y}$, and defining $K_{A}=u K$ and $K_{Y}=(1-u) K$, where $K$ is total capital and $u$ is the proportion of capital employed in the R\&D sector, this technology can be rewritten as

$$
\frac{\dot{A}}{A}=\delta s^{\gamma} u^{1-\gamma} \widetilde{k}^{1-\gamma} L
$$

so that constant population is needed for a BGP to exist. Therefore, the introduction of capital in the $R \& D$ technology does not necessarily eliminate the economy of the scale effects. ${ }^{4,5}$ This happens if the knowledge spillover is such that the cost of innovation is directly related to population. Then, let us introduce some type of externality as, for example, the diffusion of the innovation among the population. Thus, let us consider the following technology of an R\&D firm:

$$
\dot{A}=\delta\left(A L_{A}\right)^{\gamma} K_{A}^{1-\gamma}(\varepsilon L)^{-1},
$$

where $\varepsilon>0$ and $\varepsilon L$ is the diffusion externality, such that the higher the $\varepsilon$, the lower the rate of diffusion of the innovation or new good among the population. Implicit to this is that an invention will generate new inventions the more people that use the initial invention and, thus, the larger the population, the longer this may take. ${ }^{6}$ In the words of Dinopoulos and Segerstrom (1999), “... it is

\footnotetext{
${ }^{4}$ Eicher and Turnovsky (1999) also introduce capital in the R\&D production function but they still have relative scale effects, so that they have zero income growth in the absence of population growth.

${ }^{5}$ Note that the fact that capital and ideas enter both the final goods and R\&D technologies with constant returns to scale at the aggregate level does not give rise to endogenous growth. Note also that this linearity is similar to that assumed in the human capital literature.

${ }^{6}$ I owe this sentence to an anonymous referee.
} 
more difficult to introduce successfully new products and to replace old ones in a larger market". And according to Sequeira et al. (2016), the larger the market size, the greater the costs necessary to discover, develop and market the associated technology. ${ }^{7}$ Most of the literature assumes the market size to be the current knowledge or number of goods - see Aghion and Howitt (1998), Young (1998), Peretto (1998), Peretto and Smulders (2002) and Ha and Howitt (2007). But, as shown by Ang and Madsen (2013), the number of goods is in turn proportional to the size of the population in the BGP, which is the ultimate cause of the elimination of the scale effects. Contrary to the argument presented here, the idea in these papers is that a larger population increases the number of people who can enter an industry whith a new product, thus resulting in more innovations, which dilutes $\mathrm{R} \& \mathrm{D}$ expenditure over a larger number of individual projects. Other interesting examples of technology diffusion are presented by Comin and Hobijn (2010) and Desmet and Rossi-Hansberg (2014). Note that the diffusion externality assumed counterbalances the positive scale effects but not exactly, since population still affects growth due to the public nature of knowledge. Note also that the case where $\gamma=1$ does not coincide with Romer's and Jones' R\&D technologies because of different externalities. ${ }^{8}$ We can now rewrite the two technologies governing the economy as

$$
\widetilde{y}=(1-s)^{\alpha}(1-u)^{1-\alpha} \widetilde{k}^{1-\alpha}
$$

and

$$
\frac{\dot{A}}{A}=\delta \varepsilon^{-1} s^{\gamma} u^{1-\gamma} \widetilde{k}^{1-\gamma},
$$

so that the sole requirement for a BGP to exist is for $\widetilde{k}$ to be constant. Note that equation (2) shows that in a BGP there is a positive relation between the fraction of income allocated to R\&D expenditure and growth. ${ }^{9}$

Three facts should be stressed. First, the exact externality in the R\&D technology is crucial for the results, which is similar in spirit to that required in Romer (1986). Thus, any other kind of externality needs to be suitably counterbalanced in order to reach a BGP. Otherwise, income growth would not be possible without population growth. Second, population growth can affect income growth, but it is not necessary for growth to occur. That is, with constant population we have several values of $s, u$ and $\widetilde{k}$ and, then, growth; population growth, by affecting these variables, will affect growth. And third, growth depends on the probability of $R \& D$ success, which after all seems quite natural. We analyze these facts in the next section.

\footnotetext{
${ }^{7}$ Sequeira et al. (2016) introduce the concept of entropy to eliminate the existence of scale effects in the long run.

${ }^{8}$ In this case, we have $\dot{A} / A=\delta \varepsilon^{-1} s$, a kind of technology dismissed by Jones (1995). This is the reason for which we assume $\gamma \in(0,1)$.

${ }^{9}$ Note also that equation (2) satisfies the condition for the existence of endogenous growth shown in Dalgaard and Kreiner (2003): the marginal product of knowledge in producing new knowledge converges towards some positive constant in the long run.
} 


\section{The market economy}

There are three sectors in this economy. A competitive research sector uses labor and intermediate goods to produce new designs. A monopolistically competitive intermediate goods sector uses these designs and foregone output to produce inputs for the research sector and a final goods sector. Apart from the intermediate goods, the competitive final goods sector uses labor to produce final output, which can be either consumed or saved. Thus, there are two basic inputs, capital (intermediate goods) and labor, whose productivity is affected by the state of technology. Capital is measured in units of consumption goods. Since there is a monopolistic sector and knowledge is a public good, the decentralized equilibrium is not efficient.

Final goods firms: Final output $Y$ is produced with intermediate goods and labor. ${ }^{10}$ The firm's problem is

$$
\operatorname{Max} L_{Y}^{\alpha}\left(\int_{0}^{A} x_{Y}^{i}{ }^{1-\alpha} d i\right)-w_{Y} L_{Y}-\int_{0}^{A} p_{i} x_{Y}^{i} d i
$$

where the production function is à la Dixit-Stiglitz, $x_{Y}^{i}$ is the quantity of the intermediate good $i$ used to produce final goods, $A$ measures the number of available designs of intermediate goods in the economy, $w_{Y}$ is the wage paid in this sector, and $p_{i}$ is the price of the intermediate good $i$. The optimal conditions are

$$
w_{Y}=\alpha L_{Y}^{\alpha-1}\left(\int_{0}^{A} x_{Y}^{i 1-\alpha} d i\right)=\frac{\alpha Y}{L_{Y}}
$$

and

$$
p_{i}=(1-\alpha) L_{Y}^{\alpha} x_{Y}^{i-\alpha} .
$$

R\&D firms: The technology of an R\&D firm that produces the amount of new designs $\dot{A}$ is

$$
\dot{A}=\delta L_{A}^{\gamma}\left(\int_{0}^{A} x_{A}^{i 1-\gamma} d i\right)(\varepsilon L)^{-1},
$$

where $x_{A}^{i}$ is the quantity of the intermediate good $i$ used to produce all new designs. The firm's problem is

$$
\operatorname{Max} p_{A} \delta L_{A}^{\gamma}\left(\int_{0}^{A} x_{A}^{i 1-\gamma} d i\right)(\varepsilon L)^{-1}-w_{A} L_{A}-\int_{0}^{A} p_{i} x_{A}^{i} d i,
$$

where $p_{A}$ is the price of a design, and $w_{A}$ is the wage paid in this sector. The optimal conditions are

$$
w_{A}=\gamma p_{A} \delta L_{A}^{\gamma-1}\left(\int_{0}^{A} x_{A}^{i 1-\gamma} d i\right)(\varepsilon L)^{-1}=\frac{\gamma p_{A} \dot{A}}{L_{A}}
$$

\footnotetext{
${ }^{10}$ We maintain the same notation as in the previous section.
} 
and

$$
p_{i}=(1-\gamma) p_{A} \delta L_{A}^{\gamma} x_{A}^{i-\gamma}(\varepsilon L)^{-1} .
$$

Intermediate goods firms: A producer of an intermediate good purchases a design created in the R\&D sector, which grants it monopoly power over that particular good. As in Romer (1990), a putty-putty technology is considered, where the producer needs 1 unit of final good to produce 1 unit of intermediate good. The problem faced by each firm $i$ is how to maximize profits $\pi_{i}=p_{i}\left(x_{Y}^{i}+x_{A}^{i}\right)-(r+\lambda)\left(x_{Y}^{i}+x_{A}^{i}\right)$, subject to their inverse demand functions, equations (4) and (7), and where $r$ is the interest rate and $\lambda$ is the depreciation rate. Moreover, since discrimination is not allowed, the price of the intermediate good has to be the same for all buyers, so that

$$
(1-\alpha) L_{Y}^{\alpha} x_{Y}^{i-\alpha}=(1-\gamma) p_{A} \delta L_{A}^{\gamma} x_{A}^{i-\gamma}(\varepsilon L)^{-1} .
$$

Using the constraints, firm $i$ 's problem becomes

$$
\operatorname{Max} \quad \pi_{i}=\left(p_{i}-r-\lambda\right)\left(\frac{(1-\alpha)^{\frac{1}{\alpha}} L_{Y}}{p_{i}^{\frac{1}{\alpha}}}+\frac{\left[(1-\gamma) p_{A} \delta(\varepsilon L)^{-1}\right]^{\frac{1}{\gamma}} L_{A}}{p_{i}^{\frac{1}{\gamma}}}\right) .
$$

Using equations (4) and (7), the optimal condition can be written as

$$
p_{i}=(r+\lambda)\left[\frac{\gamma x_{Y}^{i}+\alpha x_{A}^{i}}{\gamma(1-\alpha) x_{Y}^{i}+\alpha(1-\gamma) x_{A}^{i}}\right],
$$

from where profits are

$$
\pi_{i}=\left(x_{Y}^{i}+x_{A}^{i}\right) p_{i}\left(\frac{\alpha \gamma x_{Y}^{i}+\alpha \gamma x_{A}^{i}}{\gamma x_{Y}^{i}+\alpha x_{A}^{i}}\right) .
$$

Households: The problem of a dynasty is

$$
\begin{gathered}
\quad \operatorname{Max} \int_{0}^{\infty} e^{-(\rho-n) t}\left(\frac{c^{1-\sigma}-1}{1-\sigma}\right) d t \\
\text { s.t. } \quad \dot{a}=\left[s w_{A}+(1-s) w_{Y}\right]+(r-n) a-c,
\end{gathered}
$$

where $a$ is per capita assets, $c$ is consumption per capita, $\rho$ is the discount time factor, and $\sigma>0$. The Euler condition is

$$
\frac{\dot{c}}{c}=\frac{(r-\rho)}{\sigma} .
$$

Market clearing conditions: Labor market equilibrium means that wages must be the same regardless of the firm. Thus, equations (3) and (6) imply

$$
\alpha L_{Y}^{\alpha-1}\left(\int_{0}^{A} x_{Y}^{i 1-\alpha} d i\right)=\frac{\alpha Y}{L_{Y}}=\frac{\gamma p_{A} \dot{A}}{L_{A}}=\gamma p_{A} \delta L_{A}^{\gamma-1}\left(\int_{0}^{A} x_{A}^{i}{ }^{1-\gamma} d i\right)(\varepsilon L)^{-1} .
$$


Since it takes 1 unit of final good to produce 1 unit of intermediate good, capital is related to the number of intermediate goods. Therefore, total usage of capital in each sector is

$$
K_{Y}=\int_{0}^{A} x_{Y}^{i} d i \text { and } K_{A}=\int_{0}^{A} x_{A}^{i} d i
$$

Assets in this economy are capital and patents. Therefore,

$$
a=k+\frac{p_{A} A}{L},
$$

where $k$ is capital per capita, which means that

$$
\dot{a}=\dot{k}+\frac{\dot{p}_{A} A}{L}+\frac{p_{A} \dot{A}}{L}-\frac{p_{A} A n}{L} .
$$

The price of a new design reflects the incentives of the producers of intermediate goods to acquire it. Following Grossman and Helpman (1991), we can state that, at any point in time, the instantaneous excess of revenue over the marginal cost must be just sufficient to cover the interest cost on the initial investment in a design. Or, in other words, the price of a design is equal to the present value of the net revenue that a monopolist can extract. In our case, that means $\pi_{i}+\dot{p}_{A}=r p_{A}$, which combined with equation (10) implies

$$
r=\left(\frac{p_{i}}{p_{A}}\right)\left(x_{Y}^{i}+x_{A}^{i}\right)\left(\frac{\alpha \gamma x_{Y}^{i}+\alpha \gamma x_{A}^{i}}{\gamma x_{Y}^{i}+\alpha x_{A}^{i}}\right)+\frac{\dot{p}_{A}}{p_{A}} .
$$

Symmetric equilibrium and BGP: In a symmetric equilibrium all the intermediate goods firms produce the same quantity with the same amount of inputs, so that $x_{Y}^{i}=x_{Y} \forall i, \int_{0}^{A} x_{Y}^{i} d i=A x_{Y}$ and $\int_{0}^{A} x_{Y}^{i}{ }^{1-\alpha} d i=A x_{Y}^{1-\alpha}$, and $x_{A}^{i}=x_{A} \forall i, \int_{0}^{A} x_{A}^{i} d i=A x_{A}$ and $\int_{0}^{A} x_{A}^{i}{ }^{1-\gamma} d i=A x_{A}{ }^{1-\gamma}$. In a BGP, the proportions of labor and capital used in each sector are constant, so that $s$ and $u$ are constant. Therefore, the equations in (13) can be rewritten as

$$
x_{Y}=\frac{(1-u) K}{A} \text { and } \quad x_{A}=\frac{u K}{A} .
$$

Combining equations (5), (8) and the final goods production function gives

$$
\frac{(1-\alpha) Y}{A x_{Y}}=\frac{(1-\gamma) p_{A} \dot{A}}{A x_{A}},
$$

which, using equations (12) and (15), becomes

$$
\frac{1-s}{s}=\frac{1-u}{u} \frac{1-\gamma}{\gamma} \frac{\alpha}{1-\alpha}
$$


From the final goods production function and equation (15), in a BGP we have $\dot{Y} / Y=\dot{A} / A+n$. Using this fact, differentiating the log of equation (12) and noting that $\ddot{A} / \dot{A}=\dot{A} / A$, yields $\dot{p}_{A} / p_{A}=n$. Using this equation and equation (15), equation (14) becomes

$$
(r-n)=\left(\frac{p_{i}}{p_{A}}\right)\left(\frac{K}{A}\right)\left[\frac{\alpha \gamma(1-u)+\alpha \gamma u}{\gamma(1-u)+\alpha u}\right] .
$$

Using equations (9), (15) and (12) yields

$$
\frac{p_{i}}{p_{A}}=\left[\frac{\gamma(1-u)+\alpha u}{\gamma(1-\alpha)(1-u)+\alpha(1-\gamma) u}\right]\left[\frac{\gamma}{\alpha} \frac{\dot{A}}{Y} \frac{(1-s)}{s}(r+\lambda)\right] .
$$

And combining these last two equations gives

$$
(r-n)=\left[\frac{\alpha \gamma}{\gamma(1-\alpha)(1-u)+\alpha(1-\gamma) u}\right]\left[\frac{\gamma}{\alpha} \frac{K}{A} \frac{\dot{A}}{Y} \frac{(1-s)}{s}(r+\lambda)\right] .
$$

Reordering equation (9) so that we eliminate the fraction, substituting in the resulting equation one $p_{i}$ from equation (4) and the other $p_{i}$ from equation (7), summing up for $i$, using the final goods production function and equations (5) and (15) and after that (16), gives

$$
(r+\lambda) K[\gamma(1-u)+\alpha u]=(1-\alpha) Y\left[\gamma(1-\alpha)+\alpha(1-\gamma) \frac{u}{1-u}\right] .
$$

Equations (5) and (15) yield

$$
g=\left(\frac{\delta}{\varepsilon}\right) s^{\gamma} u^{1-\gamma}\left(\frac{K}{A L}\right)^{1-\gamma},
$$

where $g$ is the growth rate. Combining the final goods production function with equation (15) gives

$$
\frac{Y}{K}=(1-s)^{\alpha}(1-u)^{1-\alpha}\left(\frac{A L}{K}\right)^{\alpha} .
$$

And combining equations (11), (18) and (19) yields

$$
(\sigma g+\rho-n)=\left[\frac{\alpha \gamma}{\gamma(1-u)+\alpha u}\right]\left[\frac{(1-s)}{s} \frac{(1-\alpha)}{\alpha} \frac{\gamma g}{(1-u)}\right] .
$$

Finally, combining equations (11), (17), (19), (20) and (21) gives

$$
(\sigma g+\rho+\lambda)=(1-\alpha)\left[\frac{\gamma(1-\alpha)(1-u)+\alpha(1-\gamma) u}{\gamma(1-u)+\alpha u}\right]\left[\frac{1-\gamma}{\gamma} \frac{\alpha}{1-\alpha}\right]^{\alpha}\left(\frac{\delta}{\varepsilon} \frac{s}{g}\right)^{\frac{\alpha}{1-\gamma}} .
$$

Equations (17), (22) and (23) implicitly give the growth rate of the economy. 


\section{The contribution of population to income growth}

We illustrate the contribution of population to income growth by means of a numerical exercise. First, we calibrate certain parameters of the decentralized BGP taking into account a benchmark economy. Second, we modify population growth to determine how much this affects income growth. And, third, we complete a robustness analysis.

We fix the value of the parameters as follows. $\sigma=2$, so that the intertemporal elasticity of substitution is 0.5 . The population growth rate $n$ is $1 \%$. The interest rate $r$ equals $5.2 \%$ and $\rho=0.012$, so that the growth rate is $2 \%$. In order to find the values of $\alpha$ and $\gamma$, we assume that the labor income share in the national income is $65 \%$ while the asset income share is $35 \%$. Thus, and following Echevarria (1997), we have that

$$
w_{A} L_{A}+w_{Y} L_{Y}=0.65 G D P,
$$

which can be rewritten as

$$
\frac{w_{A} L_{A}}{p_{A} \dot{A}} \frac{p_{A} \dot{A}}{G D P}+\frac{w_{Y} L_{Y}}{Y} \frac{Y}{G D P}=0.65 .
$$

From Jones and Williams (2000), we have that R\&D spending to GDP, $p_{A} \dot{A} / G D P=$ $3.1 \%$, so that $Y / G D P=96.9 \%{ }^{11}$ Thus, and substituting equations (3) and (6), the previous equation becomes

$$
\gamma 0.031+\alpha 0.969=0.65
$$

From Chapter 3 of the National Science Board (2012), we set $s=5 \%$. Then, from equations (17), (22) and (24), we recover $\alpha=0.66, \gamma=0.32$ and $u=17.97 \% .{ }^{12}$ By fixing $K / Y=2.5$, equation (19) gives $\lambda=2.2 \%$. Finally, equation (23) gives the discovering probability net of the diffusion externality $\delta \varepsilon^{-1}=0.19 .{ }^{13}$ The summary of the calibration analysis is shown in the middle column of Table 1. Note that the R\&D sector is much more capital intensive than the final goods

\footnotetext{
${ }^{11}$ See footnote 15 of their paper, where they think of this number as a lower bound.

12 This value of $\gamma$ implies that the labor share in R\&D is slightly lower than that shown for industrial sectors in Robbins et al. (2013), Table 1, where it ranges from 0.4 to 0.6. See also Verba (2015), Table A1.

${ }^{13}$ Caballero and Jaffe's (1993) estimates of the discovering probability range between 0.2 and 0.38 . Here, the discovering probability is net of the diffusion externality. This means that, ceteris paribus, by augmenting the share of population devoted to R\&D by $1 \%$, the instantaneous increase in goods or knowledge that is effectively spread through (or enjoyed by) the population is $0.19 \%$.
} 
sector, which highlights the importance of capital in the production of ideas. ${ }^{14}$

\begin{tabular}{|c|c|c|c|}
\hline R\&D \% & $\mathbf{1 . 5}$ & $\mathbf{3 . 1}$ & $\mathbf{6 . 2}$ \\
\hline $\boldsymbol{\gamma}$ & 0.31 & 0.32 & 0.33 \\
$\boldsymbol{\alpha}$ & 0.65 & 0.66 & 0.67 \\
$\mathbf{u} \%$ & 17.91 & 17.97 & 18.07 \\
$\boldsymbol{\lambda} \%$ & 2.4 & 2.2 & 1.8 \\
$\boldsymbol{\delta} \boldsymbol{\varepsilon}^{-1}$ & 0.19 & 0.19 & 0.19 \\
\hline
\end{tabular}

Table 2 shows the effect of population growth on income growth. We have to solve equations (17), (22) and (23), since the interest rate is now endogenous. Note that since the discount rate is $(\rho-n)>0$, we have an upper bound for $n$. An increase in population growth raises income growth as a result of a higher proportion of labor and capital employed in the R\&D sector. Growth is $22 \%$ higher if population growth increases from zero to $1 \%$. Or, in other words, growth is $18 \%$ lower if population growth falls from $1 \%$ to zero. Thus, we can state that population growth can explain one fifth of income growth.

\begin{tabular}{|c|c|c|c|c|c|}
\hline $\mathbf{n} \%$ & $\mathbf{0}$ & $\mathbf{0 . 2}$ & $\mathbf{0 . 5}$ & $\mathbf{1}$ & $\mathbf{1 . 1}$ \\
\hline $\mathbf{g} \%$ & 1.64 & 1.71 & 1.82 & 2 & 2.04 \\
$\mathbf{u} \%$ & 14.28 & 15 & 16.09 & 17.97 & 18.35 \\
$\mathbf{s} \%$ & 3.85 & 4.07 & 4.40 & 5 & 5.12 \\
\hline
\end{tabular}

By means of a robustness analysis, we repeat the same exercise when $R \& D$ spending is 1.5 and $6.2 \%$ of GDP (half and twice that of Jones and Williams, 2000). The results of the calibration are in Table 1. As we can observe, when R\&D spending increases, labor intensiveness remains almost the same in both the final goods and the R\&D sectors. Then, and not surprisingly, we obtain insignificant changes in the numbers of Table 2, so that the effects of population growth on income growth remain.

Second, we change the target of $s$ to 4 and $6 \%$. Although labor intensiveness in the R\&D sector changes (see Table 3), the effects of population growth on income growth are the same as those in the case of $s=5 \%$ (see Table 4).

\begin{tabular}{|c|c|c|c|}
\hline $\mathbf{s} \%$ & $\mathbf{4}$ & $\mathbf{5}$ & $\mathbf{6}$ \\
\hline $\boldsymbol{\gamma}$ & 0.27 & 0.32 & 0.37 \\
$\boldsymbol{\alpha}$ & 0.66 & 0.66 & 0.66 \\
$\mathbf{u} \%$ & 18.21 & 17.97 & 17.42 \\
$\boldsymbol{\lambda} \%$ & 2.69 & 2.2 & 1.74 \\
$\boldsymbol{\delta} \boldsymbol{\varepsilon}^{-1}$ & 0.23 & 0.19 & 0.17 \\
\hline
\end{tabular}

\footnotetext{
${ }^{14}$ This is in contrast with the human capital literature, where it is commonly assumed that
} the final goods sector is more capital intensive than the human capital sector. 


\begin{tabular}{|c|c|c|c|c|c|c|c|c|c|c|}
\hline $\mathbf{n} \%$ & \multicolumn{2}{|c|}{$\mathbf{0}$} & \multicolumn{2}{|c|}{$\mathbf{0 . 2}$} & \multicolumn{2}{|c|}{$\mathbf{0 . 5}$} & \multicolumn{2}{|c|}{$\mathbf{1}$} & \multicolumn{2}{|c|}{$\mathbf{1 . 1}$} \\
\hline Target s & $\mathbf{4}$ & $\mathbf{6}$ & $\mathbf{4}$ & $\mathbf{6}$ & $\mathbf{4}$ & $\mathbf{6}$ & $\mathbf{4}$ & $\mathbf{6}$ & $\mathbf{4}$ & $\mathbf{6}$ \\
\hline $\mathbf{g} \%$ & 1.63 & 1.64 & 1.71 & 1.71 & 1.82 & 1.82 & 2 & 2 & 2.04 & 2.04 \\
$\mathbf{u} \%$ & 14.59 & 13.74 & 15.30 & 14.45 & 16.37 & 15.54 & 18.21 & 17.42 & 18.58 & 17.80 \\
$\mathbf{s} \%$ & 3.10 & 4.60 & 3.27 & 4.86 & 3.54 & 5.27 & 4 & 6 & 4.10 & 6.15 \\
\hline
\end{tabular}

\section{Population and efficient growth}

Next, we determine whether population has the same effects on efficient income growth. Rewriting equations (1) and (2) in per capita variables, the social planner problem is

$$
\operatorname{Max} \int_{0}^{\infty} e^{-(\rho-n) t}\left(\frac{c^{1-\sigma}-1}{1-\sigma}\right) d t
$$

s.t. $\quad \dot{k}=y-c-(n+\lambda) k=(1-s)^{\alpha}(1-u)^{1-\alpha} A^{\alpha} k^{1-\alpha}-c-(n+\lambda) k$

and

$$
\dot{A}=\delta \varepsilon^{-1} s^{\gamma} u^{1-\gamma} A^{\gamma} k^{1-\gamma},
$$

where $y$ is production per capita. The first order conditions with respect to $c$, $s, u, k$ and $A$ can be written, respectively, as

$$
\begin{gathered}
c^{-\sigma}-\beta=0, \\
-\alpha y(1-s)^{-1} \beta+\gamma s^{-1} \dot{A} \xi=0, \\
-(1-\alpha) y(1-u)^{-1} \beta+(1-\gamma) u^{-1} \dot{A} \xi=0, \\
(1-\alpha) y k^{-1} \beta-(n+\lambda) \beta+(1-\gamma) k^{-1} \dot{A} \xi=-\dot{\beta}+(\rho-n) \beta
\end{gathered}
$$

and

$$
\gamma A^{-1} \dot{A} \xi+\alpha A^{-1} y \beta=-\dot{\xi}+(\rho-n) \xi,
$$

where $\beta$ and $\xi$ are the multipliers associated with equations (25) and (26), respectively.

In a BGP, from equations (28) and (29) we have that the relationship between capital and labor used between sectors satisfies

$$
\frac{1-s}{s}=\frac{1-u}{u} \frac{1-\gamma}{\gamma} \frac{\alpha}{1-\alpha} .
$$

Differentiating equations (27) and (28) with respect to time, and noting that in a BGP $\ddot{A} / \dot{A}=\dot{A} / A=g$, we have

$$
-\sigma g=\frac{\dot{\beta}}{\beta}=\frac{\dot{\xi}}{\xi} .
$$


Substituting for $\beta$ in equation (31) from equation (29), and using equations (32) and (33) we obtain

$$
s=\frac{\gamma g}{\sigma g+\rho-n} .
$$

Note that $\operatorname{sign}(\partial g / \partial s)>0$, and using equation (32) we have $\operatorname{sign}(\partial g / \partial u)>0$, too. Substituting for $\xi$ in equation (30) from equation (28), using equations (32) and (33), substituting for $y k^{-1}$ from equation (1) and after for $A k^{-1}$ from equation (26), and finally using equations (32) and (34), yields

$$
(\sigma g+\rho+\lambda)(\sigma g+\rho-n)^{\frac{\alpha}{1-\gamma}}=(1-\alpha)\left(\frac{\delta \gamma}{\varepsilon}\right)^{\frac{\alpha}{1-\gamma}}\left(\frac{1-\gamma}{\gamma} \frac{\alpha}{1-\alpha}\right)^{\alpha}
$$

Given this equation, it is clear that there is only one BGP. Moreover, sign $(\partial g / \partial n)$ $>0$. The effect of population growth on income growth differs from that in the Ramsey-Cass-Koopmans model, where population growth has no effect on the steady state. In principle, the higher the population growth, the greater the amount of final goods that have to be dedicated to capital maintenance and, then, the lower the amount of labor dedicated to R\&D. In the Ramsey-CassKoopmans model, the planner's weight on the future increases with population in such a way that it offsets capital maintenance. In our economy, this increase in the preference over the future means the social planner directly increases the amount of resources devoted to R\&D. ${ }^{15}$

In order to show how much population growth affects the efficient income growth, we apply the calibrated parameters of the benchmark economy with $3.1 \%$ of R\&D spending to GDP and $s=5 \%$ to equations (32), (34) and (35). Results are in Table 5. Efficient growth is 2.3 times that of market growth due to both the public good nature of knowledge and the fact that the social planner assigns the resources in a marginal (competitive) way, solving the surplus appropriation (monopolistic competition) problem. Growth is $6.5 \%$ higher if population growth increases from zero to $1 \%$. Or, in other words, growth is $6.1 \%$ lower if population growth falls from $1 \%$ to zero. Thus, we can state that population growth can only explain one sixteenth of efficient growth. This means that population is not as important for growth when both inefficiencies are removed. This result is in accordance with Jones (1995): with no external returns in the $\mathrm{R} \& \mathrm{D}$ sector, the surplus appropriation is the only problem the social planner has to deal with, resulting in overly low shares of labor and capital devoted to R\&D in the market economy (pp. 771-772). The difference is that whereas in Jones (1995) an increase in population growth increases growth (in the same quantity in both the market and efficient economes), which in turn increases the shares of inputs devoted to $\mathrm{R} \& \mathrm{D}$, here the increase in population growth increases the shares of inputs devoted to $\mathrm{R} \& \mathrm{D}$, which in turn increase growth. Then, an increase in population growth has necessarily greater effects

\footnotetext{
${ }^{15}$ In order to clarify the intuition, change the social planner discount factor to $\bar{\rho}$, such that $\bar{\rho}=\rho-n$ in our model. Then, it is straightforward to show that $\operatorname{sign}(\partial g / \partial n)<0$.
} 
on growth when the inefficiencies are not removed.

\begin{tabular}{|c|c|c|c|c|c|}
\hline $\mathbf{n} \%$ & $\mathbf{0}$ & $\mathbf{0 . 2}$ & $\mathbf{0 . 5}$ & $\mathbf{1}$ & $\mathbf{1 . 1}$ \\
\hline g \% & 4.32 & 4.38 & 4.46 & 4.60 & 4.63 \\
$\mathbf{u} \%$ & 40.37 & 40.98 & 41.91 & 43.47 & 43.78 \\
s \% & 13.99 & 14.30 & 14.77 & 15.59 & 15.76 \\
\hline
\end{tabular}

\section{Conclusions}

We have proposed an $\mathrm{R} \& \mathrm{D}$-variety growth model with positive income growth even in the absence of population growth. We calculate the contribution of population growth to economic growth and, hence, we show the contribution to growth of the public good nature of knowledge. We find that population growth explains one fifth of market income growth but only one sixteenth of efficient income growth. This means that population is not as important for growth when inefficiencies are removed. Clearly, future analyses should focus on the technology for the production of knowledge or R\&D technology and its microfoundations. 


\section{References}

[1] Aghion, P., Blundell, R., Griffith, R., Howitt, P. and Prantl, S. (2004). Entry and Productivity Growth: Evidence from Microlevel Panel Data. Journal of the European Economic Association, 2, 265-276.

[2] Aghion, P. and Howitt, P. (1998). Endogenous Growth Theory. The MIT Press, Cambridge.

[3] Álvarez-Peláez, M.J. and Groth, C. (2005). Too little or too much R\&D? European Economic Review, 49, 437-456.

[4] Ang, J.B. and Madsen, J.B. (2013). What drives ideas production across the world? Macroeconomic Dynamics, 19, 79-115.

[5] Bernard, A.B., Redding, S.J. and Schott, P.K. (2010). Multi-Product Firms and Product Switching. American Economic Review, 100, 70-97.

[6] Bils, M. and Klenow, P.J. (2001). The Acceleration in Variety Growth. American Economic Review (AEA Papers and Proceedings), 91, 274-280.

[7] Blundell, R., Griffith, R. and Van Reenen, J. (1999). Market Share, Market Value and Innovation in a Panel of British Manufacturing Firms. Review of Economic Studies, 66, 529-554.

[8] Caballero, R.J. and Jaffe, A.B. (1993). How High are the Giants' Shoulders: An Empirical Assessment of Knowledge Spillovers and Creative Destruction in a Model of Economic Growth, in NBER Macroeconomics Annual 1993, Cambridge: The MIT Press, 15-86.

[9] Ciccone, A. and Hall, R.E. (1996). Productivity and the Density of Economic Activity. American Economic Review, 86, 54-70.

[10] Comin, D. and Hobijn, B. (2010). An Exploration of Technology Diffusion. American Economic Review, 100, 2031-2059.

[11] Dalgaard, C.-J. and Kreiner, C.T. (2003). Endogenous Growth: A Knife Edge or the Razor's Edge? Scandinavian Journal of Economics, 105, 73-85.

[12] Davis, M.A., Fisher, J.D.M. and Whited, T.M. (2014). Macroeconomic Implications of Agglomeration. Econometrica, 82, 731-764.

[13] Desmet, K. and Rossi-Hansberg, E. (2014). Spatial Development. American Economic Review, 104, 1211-1243.

[14] Dinopoulos, E. and Segerstrom, P. (1999). A Schumpeterian Model of Protection and Relative Wages. American Economic Review, 89, 450-472.

[15] Dinopoulos, E. and Thompson, P. (1998). Schumpeterian Growth without Scale Effects. Journal of Economic Growth, 3, 313-337. 
[16] Echevarría, C. (1997). Changes in Sectoral Composition Associated with Economic Growth. International Economic Review, 38, 431-452.

[17] Eicher, T.S. and Turnovsky, S. (1999). Non-Scale Models of Economic Growth. Economic Journal, 109, 394-415.

[18] Galor, O. and Weil, D.N. (2000). Population, Technology, and Growth: From Malthusian Stagnation to the Demographic Transition and Beyond. American Economic Review 90, 806-28.

[19] Geroski, P. (1995). Market Structure, Corporate Performance and Innovative Activity. Oxford University Press, Oxford.

[20] Grossman, G.M. and Helpman, E. (1991). Innovation and growth in the global economy. MIT Press, Cambridge.

[21] Ha, J. and Howitt, P. (2007). Accounting for Trends in Productivity and R\&D: A Schumpeterian Critique of Semi-Endogenous Growth Theory. Journal of Money, Credit and Banking, 39, 733-774.

[22] Jerbashian, V. (2016). Knowledge Licensing in a Model of R\&D-driven Endogenous Growth. B.E. Journal of Macroeconomics 16, 555-579.

[23] Jones, C.I. (1995). R\&D-Based Models of Economic Growth. Journal of Political Economy, 105, 759-784.

[24] Jones, C.I. (1999). Growth: With or Without Scale Effects? American Economic Review (AEA Papers and Proceedings), 89, 139-144.

[25] Jones, C.I. and Williams, J.C. (2000). Too Much of a Good Thing? The Economics of Investment in R\&D. Journal of Economic Growth, 5, 65-85.

[26] Kremer, M., (1993). Population Growth and Technological Change: One Million B.C. to 1990. Quarterly Journal of Economics, 108, 681-716.

[27] Laincz, C. and Peretto, P.F. (2006). Scale Effects in Endogenous Growth Theory: An Error of Aggregation, Not Specification. Journal of Economic Growth, 11, 263-288.

[28] Madsen, J.B. (2007). Are there diminishing returns to R\&D? Economics Letters, 95, 161-166.

[29] Madsen, J.B. (2008). Semi-endogenous versus Schumpeterian growth models: testing the knowledge production function using international data. Journal of Economic Growth, 13, 1-26.

[30] Mokyr, J. (2013). Is Technological Progress a Thing of the Past? http://www.voxeu.org/article/technological-progress-thing-past.

[31] National Science Board (2012). Science and Engineering Indicators 2012. Arlington VA: National Science Foundation (NSB 12-01). 
[32] Nickell, S.J. (1996). Competition and Corporate Performance. Journal of Political Economy, 104, 724-746.

[33] Peretto, P.F. (1998). Technological Change and Population Growth. Journal of Economic Growth, 3, 283-311.

[34] Peretto, P. and Smulders, S. (2002). Technological Distance, Growth and Scale Effects. Economic Journal, 112, 603-624.

[35] Raurich, X., Sánchez-Losada, F. and Vilalta-Bufí, M. (2015). Knowledge Misallocation and Growth. Macroeconomic Dynamics, 19, 1540-1564.

[36] Rivera-Batiz, L.A. and Romer, P.M. (1991). Economic Integration and Endogenous Growth. Quarterly Journal of Economics, 106, 531-555.

[37] Robbins, C., Belay, O., Donahoe, M. and Lee, J. (2013). Industry-level Output Price Indexes for R\&D: An Input-cost Approach with R\&D Productivity Adjustment. BEA Working Papers, WP2013-2.

[38] Romer, P.M. (1986). Increasing Returns and Long-Term Growth. Journal of Political Economy, 94, 1002-1037.

[39] Romer, P.M. (1990). Endogenous Technological Change. Journal of Political Economy, 98, S71-102.

[40] Segerstrom, P.S. (1998). Endogenous Growth Without Scale Effects. American Economic Review, 88 1290-1310.

[41] Sequeira, T., Gil, P. and Afonso, O. (2016). Growth without scale effects due to entropy. FEP Working Papers, n. 575.

[42] Strulik, H., Prettner, K. and Prskawetz, A. (2013). The Past and Future of R\&D-based Growth. Journal of Economic Growth, 18, 411-437.

[43] Venturini, F. (2012). Looking into the black box of Schumpeterian growth theories: An empirical assessment of R\&D races. European Economic Review, 56, 1530-1545.

[44] Verba, M. (2015). Growth and innovation in the presence of knowledge and R\&D accumulation dynamics. UNU-MERIT Working Papers, n. 2015-054.

[45] Young, A. (1998). Growth without Scale Effects. Journal of Political Economy, 106, 41-63.

[46] Zachariadis, M. (2003). R\&D, Innovation, and Technological Progress: A Test of the Schumpeterian Framework without Scale Effects. Canadian Journal of Economics, 36, 566-586.

[47] Zhang, J. (1995). Social security and endogenous growth. Journal of Public Economics, 58, 185-213. 
[48] Zhang, J. and Zhang, J. (2003). Long-run effects of unfunded social security with earnings-dependent benefits. Journal of Economic Dynamics and Control, 28, $617-641$. 